Научная статья

УДК 687.1

DOI https://doi.org/10.24866/VVSU/2073-3984/2021-3/147-157

М.А. Гусева ${ }^{1}$

Е.Г. Андреева ${ }^{2}$

К. кызы Али ${ }^{3}$

Российский государственный университет им. А.Н. Косыгина (Технологии. Дизайн. Искусство) Москва. Россия

\title{
Виртуальный инструментарий для комплексной оценки качества одежды со сложнофактурной поверхностью
}

\begin{abstract}
Активный образ жизни современного человека определяет выбор его повседневного гардероба. В качестве базовой плечевой одежды большинство потребителей предпочитают изделия «быстрой моды» (футболки, толстовки, куртки), силуэт, покрой и конфекцион-пакет которых обеспечивают достаточный уровень эргономического соответствия при оценке показателей качества. Цикличность моды неизбежно приводит к обновлению: потребители меняют модные привычки и модели одежды сложного кроя, прилегающего и полуприлегающего силуэтов, изготовленные из материалов сложной фактуры, периодически становятся востребованы. В настоящее время быструю смену модных тенденций сопровождает ускорение процесса проектирования одежды, основанное на включении в САПР модулей виртуальных примерок. Симуляция посадки проектируемых изделий на электронных фигурах позволяет оценить эстетический образ, качество конструктивного решения в статике и динамике. На адекватность виртуального макетирования непосредственно влияют загруженные в САПР обучающие выборки, представляющие собой базы трехмерных и плоскостных конструкций одежды и библиотеки визуализации посадки проектируемых изделий на электронных манекенах. В статье представлены результаты тестирования инструментария программы CLO3D для процесса проектирования одежды с меховой отделкой. Проведенная виртуальная примерка показала преимущество симулятивного макетирования изделий со сложной фактурной поверх-
\end{abstract}

${ }^{1}$ Гусева Марина Анатольевна - канд. техн. наук, доцент, доцент кафедры художественного моделирования, конструирования и технологии швейных изделий; e-mail: guseva_marina67@mail.ru

2 Андреева Елена Георгиевна - д-р техн. наук, профессор, профессор кафедры художественного моделирования, конструирования и технологии швейных изделий; e-mail: elenwise@mail.ru

3 Али кызы Курманжан - аспирант кафедры художественного моделирования, конструирования и технологии швейных изделий; e-mail: alikyzy@ yandex.ru 
ностью, выраженное в быстром получении результатов анализа пространственной формы исследуемых моделей на соответствие эстетических и эргономических показателей качества объектов без изготовления их натурных аналогов.

Ключевые слова и словосочетания: цифровые двойники фигур, оценка внешнего вида, динамическое соответствие.

M.A. Guseva

E.G. Andreeva

K. kyzy Aly

The Kosygin State University of Russia

Moscow. Russia

\section{Virtual toolkit for a comprehensive assessment of the quality of clothing with a complex textured surface}

The active lifestyle of a modern person determines the choice of his everyday wardrobe. Most consumers prefer "fast fashion" products (T-shirts, sweatshirts, jackets) as basic shoulder garments, the silhouette, cut and dressing package of which provide a sufficient level of ergonomic conformity when assessing quality indicators. The cyclical nature of fashion inevitably leads to renewal - consumers change fashion habits and models of clothes of complex cut, adjacent and semi-adjacent silhouettes, made from materials of complex texture, periodically become in demand. Currently, the rapid change in fashion trends is accompanied by the acceleration of the clothing design process, based on the inclusion of virtual fitting modules in CAD. Simulation of the fit of the designed products on electronic figures allows you to evaluate the aesthetic image, the quality of structures in statics and dynamics. The adequacy of virtual prototyping is directly influenced by training samples loaded into CAD, which are bases of three-dimensional and planar clothing designs and libraries for visualizing the landing of designed products on electronic dummies. The article presents the results of testing the CLO3D toolkit for the design process of clothes with fur trim. The conducted virtual fitting showed the advantages of simulative prototyping of products with a complex textured surface, expressed in the rapid obtaining of the results of the analysis of the spatial form of the studied models for compliance with aesthetic and ergonomic quality indicators of objects without making their full-scale counterparts.

Keywords: digital doubles of figures, assessment of appearance, dynamic matching.

Темпы обновления дизайнерских и промышленных коллекций меховой одежды в настоящее время соизмеримы с динамикой мировой моды на изделия из текстиля [1]. Преимуществами натурального меха как материала для одежды являются эстетичность, экологичность, долговечность [2], а серьезным недостатком - высокая стоимость. При этом на рынке представлены меховые изделия различных стоимостных категорий - от экономсегмента [3; 4] до класса LuxPremium [5; 6]. По данным агентства Ru-Stat, товарооборот России в категории «Изделия из кожи и меха» за 2020 составил \$1,14 млрд, из них экспорт $\$ 160$ млн, импорт - \$982 млн, при этом по сравнению с 2019 годом наблюдается 
М.А. Гусева и др. Виртуальный инструментарий для комплексной оценки качества одежды...

снижение показателей на 22,9\%. Спрос на продукцию меховых предприятий регулируется модными тенденциями, а также образом жизни и покупательской способностью потребителей. С появлением новых материалов [7], имитирующих пушнину, возросли продажи изделий из синтетического меха. Кроме того, меховая мода, как и мода на текстиль, подчинена законам цикличности, поэтому волнообразность в развитии индустрии и спроса на одежду из меха [8] является закономерным явлением.

Особенностью современного периода развития меховой моды стало снижение темпов производства одежды - на меховом бизнесе негативно отразилась мировая пандемия коронавируса [9]. После локдауна, с апреля по август 2020 г., продажи меховых изделий в России упали почти в 10 раз [10]. С оздоровлением экономики перед российскими производителями меховой продукции открываются новые перспективы наполнения внутреннего рынка отечественным сырьем и пушно-меховым полуфабрикатом.

В меховой индустрии наиболее востребованным видом меха признана норка [11], поэтому при анализе рынка пушно-меховой продукции основные показатели ориентированы именно на экспорт/импорт этой шкурковой продукции. В докризисный период (по данным за 2018 г.) основным поставщиком шкурок норок на мировой рынок были зверохозяйства Китая (20,6 млн шкурок), Дании (17,6 млн шт.), Польши (5 млн шт.) [9]. После череды вспышек коронавирусной инфекции среди сотрудников ведущих звероводческих ферм Европы многие норковые зверохозяйства были закрыты на карантин или ликвидированы. Так, в Дании на 284 фермах были вынуждены уничтожить 10 млн голов племенных норок, в Греции - 2500, во Франции - 1000 [9], что нанесло серьезный урон мировой меховой индустрии. По данным аукционного дома SagaFurs, в сезоне 2012-2013 гг. шкурка североамериканской норки стоила \$87,3 (66,4 евро), а в 2019-2020 гг. - всего \$16,9 (15,1 евро) [10]. Единственной страной, стойко сохранившей в период пандемии свои позиции в поставках шкурок норок на мировой рынок, остался Китай. Китайские зверозаводчики активно наполняют шкурковой продукцией внутренний и внешний рынки [12]. Использование дешевой пушнины из Китая способствует снижению качества конечного продукта - меховой одежды и, соответственно, падению спроса на меховые товары. Опрос, проведенный компанией ActAsia, показал, что более 43\% респондентов из-за низкого качества меха выбирают не цельномеховую одежду, а изделия с меховой отделкой [9].

Потрясения мировой экономики в период пандемии могут перевести деятельность звероводческих ферм и производителей меховой одежды в категорию убыточных предприятий, поскольку звероводство не вошло в перечень пострадавших от пандемии отраслей с предоставлением соответствующих преференций [12]. Одним из путей выхода из кризисной ситуации для отечественных предпринимателей должно стать внедрение нового подхода к проектированию одежды из меха - перевод предприятий отрасли в новый цифровой формат развития [13]. Проектирование изделий из меха целесообразно с использованием современных модулей трехмерного конструирования и симуляции примерок. 
Новый подход позволяет ускорить процесс, повысить качество работ на этапе дизайнерской проработки моделей и оптимизировать конструкторско-технологическое решение изделий.

Цель исследования - тестирование инструментария программы CLO3D применительно к процессу проектирования одежды с отделкой из меха норки.

Результаты исследования. Отличительной чертой модного направления последнего десятилетия стало присутствие в дизайнерских коллекциях моделей меховой одежды со сложнофактурной поверхностью [14]. Декоративность волосяной поверхности придают различными техниками соединения в полотне меховых фрагментов:

- раппортная, или орнаментальная, инкрустация (weave illusion);

- переворачивание мелких и крупных деталей при соблюдении разнонаправленности роста волосков (up|down);

- присоединение к текстилю или коже меховых фрагментов (fox on fabric, tiles, metacarpus);

- перфорация (airgalloon) [15].

В новой технике работают дизайнеры мировых Домов Мод (Fendi, Dolce\&Gabbana, Yves Salomon, Nina Ricci, Blumarine, Burberry, Miu Miu, Milly, Gucci, Ashish, Valentino Pre-Fall, Dennis Basso, Christian Dior, Dsquared, Barbara Buiy, Ralph Lauren, Stella McCartney, JC de Castelbajac, Vivienne Westwood, Peter Som) [16] и известные российские производители (Alena Akhmadullina, Emil Shabaev, Меха Екатерина). В текущем модном цикле на подиумах представлены модели одежды из меха норки, стилевая эклектика которых направлена на усиление декоративности поверхности комбинированием с двумя и более видами меха: 1) длинноволосыми (лисица, рысь, песец, енотовидная собака), 2) средневолосыми (соболь, куница, бобр), 3) стриженной овчиной или каракулем [17].

В качестве объекта исследования выбрана модель женского жакета с меховыми рукавами. Предпроектными исследованиями установлено, что отечественные потребители со средним и высоким уровнем дохода основными факторами выбора покупки меховой одежды считают дизайн (88\%), модный вид меха (83\%), брендовость вещи (79\%) и актуальность модели $(75 \%)$. Среди покупателей с низким уровнем дохода популярны меховые модели категории «эконом», а также из мехов-имитаторов, волосяная поверхность которых стилизована крашением, стрижкой, глажением под дорогую пушнину. Анализ рынка показал стабильную популярность изделий из меха норки, рыси, бобра, лисицы, енота, песца, куницы, соболя, шиншиллы, каракуля, овчины, кролика.

Особенностью процесса моделирования изделий из меха является недостаточная информативность процесса макетирования [18], поскольку из-за высокой стоимости меха в качестве материала для изготовления натурного макета традиционно используют ткань. Разность свойств основного и макетного материалов часто не позволяет достоверно оценить композиционно-конструктивное реше- 
ние модели. Цифровое макетирование в трехмерной среде дает возможность визуально приблизить свойства проектируемого объекта и повысить качество дизайнерских и конструкторских работ.

В качестве программной среды выбран трехмерный графический редактор CLO3D, который обеспечивает возможность визуализации эстетических и физикомеханических свойств материалов, симуляции примерок на трехмерном аватаре, уточнения дизайна и конструктивного решения изделия в 3D-пространстве при одновременной модификации плоскостной развёртки (рис. 1).

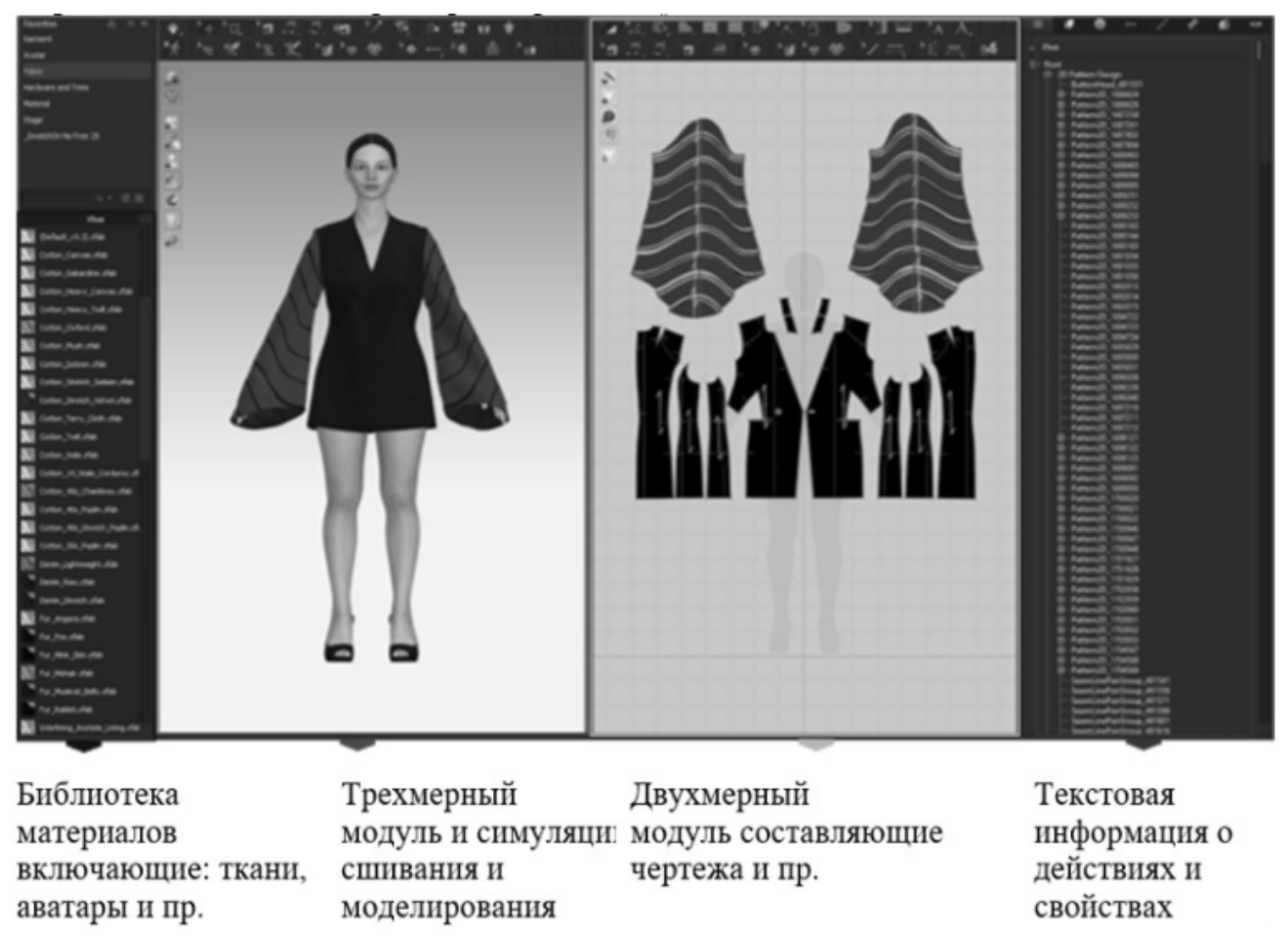

Рис. 1. Проектируемая модель жакета с меховыми рукавами в окнах пользовательского интерфейса CAПР CLO3D

База аватаров в CAПP CLO3D представляет собой библиотеку трансформируемых под индивидуальные параметры виртуальных манекенов. Удобен выбор конфигурации электронного двойника: возможно редактирование внутреннего каркаса манекена (форма скелета и позиционирование его составных частей) и внешней оболочки (цветотип, наличие и форма жироотложений, развитие мышечной массы и т.п.) (рис. 2). В зависимости от поставленных в проекте задач в САПР предусмотрено пополнение базы цифровыми двойниками сканированных полноростовых фигур [19].

Тестирование возможностей программы CLO3D продемонстрировало удобство пользования инструментом регулирования позы электронной фигуры на этапе оценки качества конструктивного решения изделия в статике и динамике. 
Поскольку тело человека - это система с управляемой координацией движений, то его можно представить в виде многозвенной кинематической цепи (рис. 2a), которой присущи определенные ограничения степеней свободы [20]. Сформировать у аватара нужную позу пользователь сможет, придав необходимые степени свободы сочлененным звеньям двигательного аппарата [21].

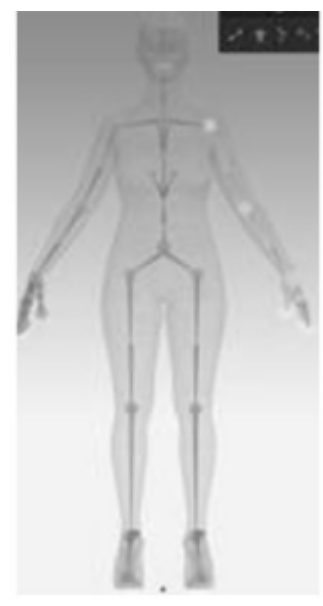

$a$

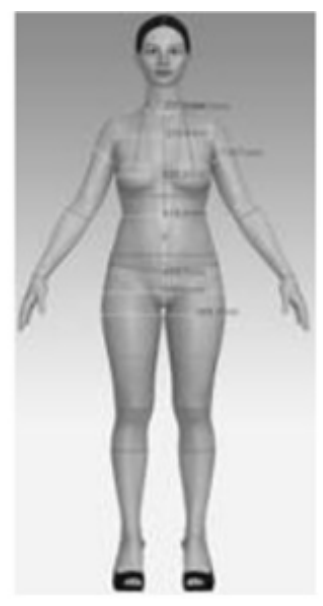

$\sigma$

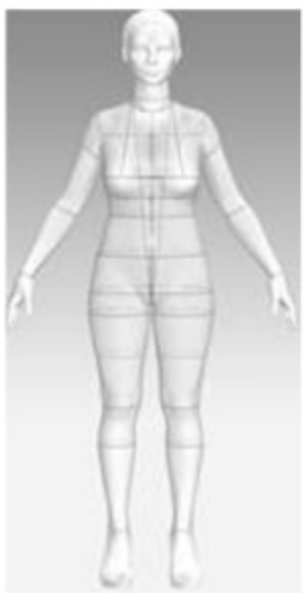

8

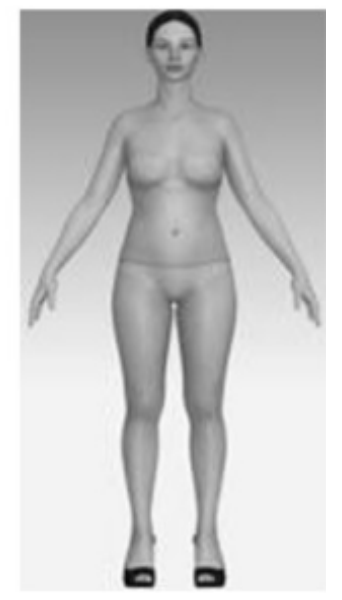

2

Рис. 2. Формирование аватара: $a$ - точечно-каркасная настройка позы; $\sigma$ - выбор параметров внешней формы фигуры; в - каркасно-прозрачная полигонная оболочка,

$$
\text { г - итоговая модель }
$$

В качестве тестируемых движений выбраны следующие движения рук аватара:

- вперед (выпрямленные и согнутые в локтях руки),

- через стороны вверх,

- разведение в стороны.

Все движения тела человека обеспечиваются упругостью и эластичностью мышечного аппарата. На основе классических схем биокинематического анализа и взаимодействия элементов системы «человек-одежда» [22; 23] авторами проведены антроподинамические исследования и выполнено моделирование соответствующих движений для электронной фигуры (рис. 3). Установлено, что при выполнении движений рук вначале происходит перемещение верхних конечностей внутри рукава, а затем внутри стана изделия. С достижением максимальной амплитуды размаха рук начинается перемещение изделия относительно фигуры человека, при этом на поверхности изделия формируются разнонаправленные складки и заломы. Виртуальная симуляция примерки макета в статике и динамике позволяет оценить достаточность (или недостаточность) объема проектируемого изделия и сделать вывод об эргономическом комфорте модели. 


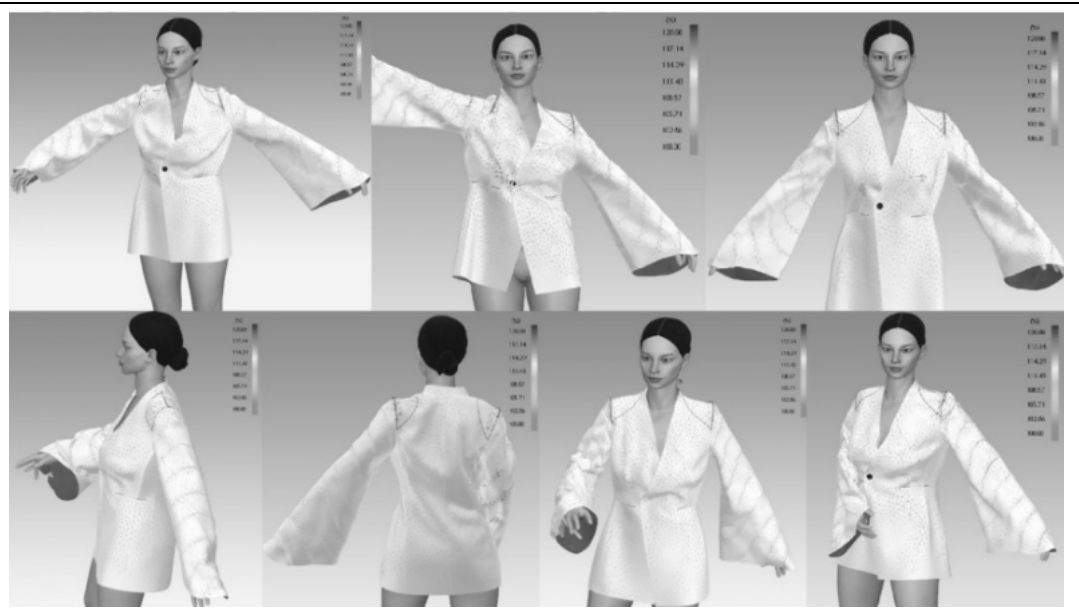

Рис. 3. Проверка на эргономическое соответствие виртуального макета (фрагмент)

В ходе виртуального эксперимента установлено, что для обеспечения эргономического комфорта в конструктивное решение проектируемого изделия необходимо внести следующие изменения: 1) выполнить расширение деталей спинки и переда по основной горизонтали - линии груди; 2) увеличить ширину рукава вверху; 3) увеличить высоту оката рукава.

Тестирование инструментария CAПР CLO3D показало достаточные возможности программы для реализации процедуры визуализации текстуры меховой поверхности. Характеристики волосяного покрова (высота, густота, извитость, блеск, цвет и др.) пользователь формирует в сопряженных графических редакторах, например, в программе Adobe Photoshop [24]. Далее при рендеризации отображается фактура меховой поверхности с заданными свойствами (инструменты object browse, physical property, weight, length, density, thickness) [1].
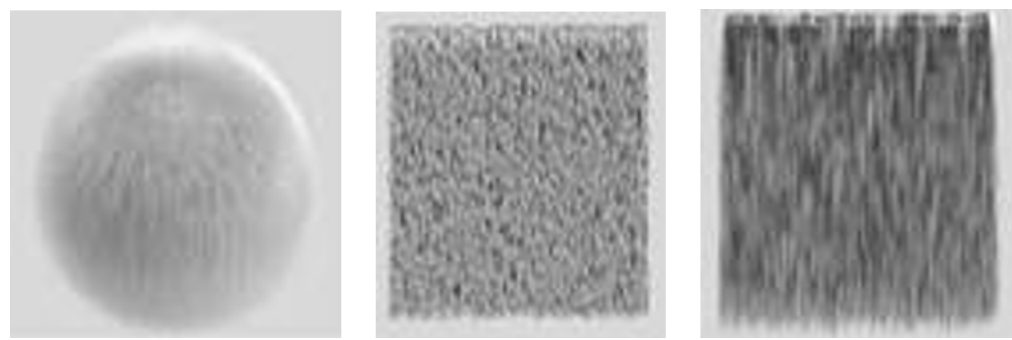

Рис. 4. Варианты проработки фактуры меховой поверхности

Экспериментально установлено, что для большего сходства виртуальной меховой поверхности с натурным аналогом необходимо не только тщательно подходить к выбору значений параметра Band (угол наклона волосков), но и представлять базовый элемент (волосок) в виде сегментной многозвенной модели (таблица). 
Некоторые характеристики базовых моделей волосков

\begin{tabular}{|l|c|c|c|c|c|c|}
\hline $\begin{array}{c}\text { Инстру- } \\
\text { мент }\end{array}$ & \multicolumn{2}{|c|}{$\begin{array}{c}\text { Угол наклона волосков } \\
\text { (Band) }\end{array}$} & \multicolumn{2}{c|}{ Густота (Density) } & \multicolumn{2}{c|}{$\begin{array}{c}\text { Сегменты } \\
\text { (Segments) }\end{array}$} \\
\hline Параметр & 1,00 & 0,20 & 1,00 & 0,20 & 2 & 4 \\
\hline $\begin{array}{l}\text { Визуали- } \\
\text { зация }\end{array}$ & & & & & & \\
\hline
\end{tabular}

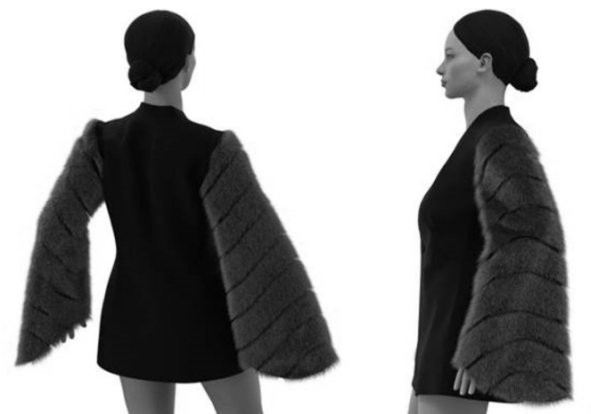

Рис. 5. Виртуальный образец изделия

Для достоверного сходства виртуальной модели и натурного аналога выполнен рендеринт текстуры поверхности рукавов (мех - крашенная норка). Каждый примитив (волосок) выполнен в виде четырехзвенной сегментной модели. Эстетические параметры, присущие меховой поверхности, сформированы сочетанием характеристик, задаваемых геометрическим примитивам (линиям) - длина (weight), толщина (thickness), блеск (glossiness), мягкость (softness), цвет (melanin).

Адекватность сходства виртуального образца и натурного аналога оценена экспертами на 4,9 балла по пятибалльной шкале (рис. 5).

Заключение. Проведенное тестирование инструментария CAПР CLO3D свидетельствует о возможности использования программы в качестве встроенного модуля для визуализации проектных и дизайнерских решений изделий с меховыми деталями. Интерактивные режимы взаимодействия пользователей и программы, открытость ее структуры позволяют расширить сферу применения CAПP CLO3D и привлечь к процессу виртуального эскизирования не только дизайнеров предприятий, но и потребителей.

1. Гусева М. А., Андреева Е. Г., Али кызы К. Визуализация меха для симуляции его фактуры в одежде. - Текст: электронный // Костюмология. - 2021. - № 2, Т. 6. URL: https://kostumologiya.ru/PDF/06TLKL221.pdf (дата обращения: 24.05.2021).

2. Муравская Н. Н., Белоногова М. Н., Куркова В. С. Исследование износостойкости пушно-меховых полуфабрикатов // Вестник Костромского государственного технологического университета. - 2013. - № 1 (30). - С. 35-37.

3. Brin I. Women's wardrobes, men's wardrobes // Art in Translation. - 2015. - Vol. 7, Special Is. 2: Fashion. - P. 254-265. 
4. Important traits in karakul lamb skin / M. Groza, I. Pădeanu, Gh. Hrincă, S. Voia, E. Fecioru, I. Chiorescu, Gh. Brădățan // Lucrari Stiintifice: Zootehniesi Biotehnologii. 2013. - Vol. 40, Is. 2. - P. 348-355.

5. Harpera C.I found myself inside her fur // Textile: The Journal of Cloth and culture. 2008. - Vol. 6, Is. 3. - P. 300-313.

6. Wilcox R. T. The mode in furs: A historical survey with 680 illustrations (Dover fashion and costumes). - Mineola, NY: Dover Publications Inc., 2010. - 272 p.

7. Белгородский В.С., Кирсанова Е.А., Мишаков В.Ю. Инновации в материалах легкой промышленности. - Москва: РГУ им. А.Н. Косыгина, 2017. - 170 с.

8. Борисова Е.Н., Койтова Ж.Ю. Оценка значимости качественных характеристик изделий из овчинного полуфабриката на основе анализа требований потребителей // Вестник Костромского государственного технологического университета. - 2013. - № 2 (31).

9. Бакиева М. Как коронавирус поставил под удар производство шуб и что будет с рынком в будущем. - Текст: электронный // FORBES: [сайт]. - URL: https://www.forbes.ru/forbeslife (дата обращения: 27.11.2020).

10. Новости пушно-меховой индустрии. - Текст: электронный // Российский пушномеховой союз: [сайт]. - URL: http://rpms.ru/novosti/zverovodstvo (дата обращения: 12.01.2021).

11. Управление эстетическими и эксплуатационными свойствами меха норки путем модификации режимов кормления / М. В. Новиков, К. Э. Разумеев, М. А. Гусева, Е.Г. Андреева // Текстильная и легкая промышленность. - 2019. - № 2-3. - С. 17-21.

12. Токманцева И. Русская норка не сможет заменить датскую. - Текст: электронный // Ведомости: [сайт].- URL: https://www.vedomosti.ru/business/articles/2020/ 12/20/851723-russkaya-norka (дата обращения: 15.05.2021).

13. Отдельные аспекты PLM-систем для создания цифровых фабрик в швейной промышленности / Н. Л. Корнилова, С. В. Салкуцан, М.В. Болсуновская [и др.] // Известия высших учебных заведений. Технология текстильной промышленности. 2018. - №4 (376). - С. 103-106.

14. Меховые элементы в дизайне одежды разного ассортимента. - Текст: электронный / М. А. Гусева, Л. Ю. Колташова, М.В. Новиков [и др.] // Костюмология. - 2020. - №2, T. 5. - URL: https://kostumologiya.ru/PDF/15TLKL220.pdf (дата обращения: 24.05.2021).

15. KOPENHAGENFUR: [сайт]. - URL: https://www.kopenhagenfur.com/ (дата обращения: 15.06.2021).

16. Xu T., Fang M., Li G.D. Study on the innovative design of fur clothing // Advanced Materials Research. - 2011. - Vol. 331, Sept. - P. 586-589.

17. Применение цифровых технологий при производстве и пошиве изделий из овчин, каракуля и шкурок пушных зверей / В.И. Трухачев, Н. А. Балакирев, В.С. Белгородский [и др.]. - Москва: Издательство РГАУ-МСХА имени К. А. Тимирязева, 2020. $140 \mathrm{c}$.

18. Анализ современного развития меховой моды. - Текст: электронный / М.А. Гусева, Л.Ю. Колташова, Е.Г. Андреева [и др.] // Костюмология. - 2020. - Т. 5, № 1. - URL: https://kostumologiya.ru/PDF/13TLKL120.pdf (дата обращения: 14.08.2021).

19. Свидетельство о регистрации базы данных RU 2019622196. База данных цифровых двойников сканированных полноростовых мужских фигур / И.В. Жукова, В.Е. Кузьмичев, Е.В. Румянцев. Зарег. 27.11.2019, бюл. № 12.

20. Сурженко Е. Я., Хлебникова Е. Л. Проектирование и оценка конструктивных параметров женских комбинезонов в системе эргономического дизайна производствен- 
ной одежды // Известия высших учебных заведений. Технология легкой промышленности. - 2013. - Т. 22, № 4. - С. 71-74.

21. Проектирование трехмерных манекенов фигуры человека / А. А. Тутова, И.А. Петросова, Е. Г. Андреева [и др.] // Известия высших учебных заведений. Технология легкой промышленности. - 2019. - Т. 43, № 1. - С. 65-70.

22. Жукова И.В., Кузьмичев В.Е. Использование реляционных баз данных разного информационного наполнения для проектирования виртуальных двойников фигур: новый тренд после FHUB IVANOVO I Физика волокнистых материалов: структура, свойства, наукоемкие технологии и материалы (SMARTEX). - 2020. - № 1. - С. 46-49.

23. Математическое моделирование процессов теплообмена в системе «человек - одежда - среда» / Н. В. Корнев, И.В. Черунова, Е.О. Лебедева [и др.].// Современные проблемы науки и образования. - 2012. - № 6. - С. 135.

24. Виртуальное $3 \mathrm{D}$-эскизирование в имитационном проектировании и конфекционировании меховой одежды / В.С. Белгородский, М. А. Гусева, Е.Г. Андреева, М.И. Алибекова // Материалы и технологии. - 2020. - №1(5). - С. 11-18.

\section{References}

1. Guseva M. A., Andreeva E. G., Ali kyzy K. Vizualizaciya mekha dlya simulyacii ego faktury v odezhde. - Tekst: elektronnyj // Kostyumologiya. - 2021. - № 2, T. 6. - URL: https://kostumologiya.ru/PDF/06TLKL221.pdf (data obrashcheniya: 24.05.2021).

2. Muravskaya N.N., Belonogova M.N., Kurkova V.S. Issledovanie iznosostojkosti pushnomekhovyh polufabrikatov // Vestnik Kostromskogo gosudarstvennogo tekhnologicheskogo universiteta. - 2013. - № 1 (30). - S. 35-37.

3. Belgorodskij V.S., Kirsanova E. A., Mishakov V. Yu. Innovacii v materialah legkoj promyshlennosti. - Moskva: RGU im. A. N. Kosygina, 2017. - 170 s.

4. Borisova E. N., Kojtova Zh. Yu. Ocenka znachimosti kachestvennyh harakteristik izdelij iz ovchinnogo polufabrikata na osnove analiza trebovanij potrebitelej // Vestnik Kostromskogo gosudarstvennogo tekhnologicheskogo universiteta. - 2013. - № 2 (31).

5. Bakieva M. Kak koronavirus postavil pod udar proizvodstvo shub $\mathrm{i}$ chto budet $\mathrm{c}$ rynkom v budushchem. - Tekst: elektronnyj // FORBES: [sajt]. - URL: https://www.forbes.ru/forbeslife (data obrashcheniya: 27.11.2020).

6. Novosti pushno-mekhovoj industrii. - Tekst: elektronnyj // Rossijskij pushno-mekhovoj soyuz: [sajt]. - URL: http://rpms.ru/novosti/zverovodstvo (data obrashcheniya: 12.01.2021).

7. Upravlenie esteticheskimi i ekspluatacionnymi svojstvami mekha norki putem modifikacii rezhimov kormleniya / M. V. Novikov, K. E. Razumeev, M. A. Guseva, E. G. Andreeva // Tekstil'naya i legkaya promyshlennost'. - 2019. - № 2-3. - S. 17-21.

8. Tokmanceva I. Russkaya norka ne smozhet zamenit' datskuyu. - Tekst: elektronnyj // Vedomosti: [sajt]. - URL: https://www.vedomosti.ru/business/articles/2020/ 12/20/851723russkaya-norka (data obrashcheniya: 15.05.2021).

9. Otdel'nye aspekty PLM-sistem dlya sozdaniya cifrovyh fabrik v shvejnoj promyshlennosti / N. L. Kornilova, S. V. Salkucan, M. V. Bolsunovskaya [i dr.] // Izvestiya vysshih uchebnyh zavedenij. Tekhnologiya tekstil'noj promyshlennosti. - 2018. - №4 (376). S. 103-106.

10. Mekhovye elementy $\mathrm{v}$ dizajne odezhdy raznogo assortimenta. - Tekst: elektronnyj / M. A. Guseva, L. Yu. Koltashova, M.V. Novikov [i dr.] // Kostyumologiya. - 2020. - №2, T. 5. - URL - https://kostumologiya.ru/PDF/15TLKL220.pdf (data obrashcheniya: 24.05.2021) 
11. Primenenie cifrovyh tekhnologij pri proizvodstve i poshive izdelij iz ovchin, karakulya $i$ shkurok pushnyh zverej / V. I. Truhachev, N. A. Balakirev, V. S. Belgorodskij [i dr.]. Moskva: Izdatel'stvo RGAU-MSKHA imeni K. A. Timiryazeva, 2020. - $140 \mathrm{~s}$.

12. Analiz sovremennogo razvitiya mekhovoj mody. - Tekst: elektronnyj / M. A. Guseva, L.Yu. Koltashova, E.G. Andreeva [i dr.] // Kostyumologiya. - 2020. - T. 5, № 1. - URL : https://kostumologiya.ru/PDF/13TLKL120.pdf (data obrashcheniya: 14.08.2021).

13. Svidetel'stvo o registracii bazy dannyh RU 2019622196. Baza dannyh cifrovyh dvojnikov skanirovannyh polnorostovyh muzhskih figur / I.V. Zhukova, V.E. Kuz'michev, E.V. Rumyancev. Zareg. 27.11.2019, byul. № 12.

14. Surzhenko E. Ya., Hlebnikova E. L. Proektirovanie i ocenka konstruktivnyh parametrov zhenskih kombinezonov $\mathrm{v}$ sisteme ergonomicheskogo dizajna proizvodstvennoj odezhdy // Izvestiya vysshih uchebnyh zavedenij. Tekhnologiya legkoj promyshlennosti. 2013. - T. 22, № 4. - S. 71-74.

15. Proektirovanie trekhmernyh manekenov figury cheloveka / A. A. Tutova, I. A. Petrosova, E. G. Andreeva [i dr.] // Izvestiya vysshih uchebnyh zavedenij. Tekhnologiya legkoj promyshlennosti. - 2019. - T. 43, № 1. - S. 65-70.

16. Zhukova I.V., Kuz'michev V.E. Ispol'zovanie relyacionnyh baz dannyh raznogo informacionnogo napolneniya dlya proektirovaniya virtual'nyh dvojnikov figur: novyj trend posle FHUB IVANOVO I Fizika voloknistyh materialov: struktura, svojstva, naukoemkie tekhnologii i materialy (SMARTEX). - 2020. - № 1. - S. 46-49.

17. Matematicheskoe modelirovanie processov teploobmena v sisteme «chelovek - odezhda sreda» / N. V. Kornev, I. V. CHerunova, E. O. Lebedeva [i dr.].// Sovremennye problemy nauki i obrazovaniya. - 2012. - № 6. - S. 135.

18. Virtual'noe 3D-eskizirovanie $\mathrm{v}$ imitacionnom proektirovanii i konfekcionirovanii mekhovoj odezhdy / V. S. Belgorodskij, M. A. Guseva, E. G. Andreeva, M.I. Alibekova // Materialy i tekhnologii. - 2020. - №1(5). - S. 11-18.

(C) М. А. Гусева, 2021

() Е.Г. Андреева, 2021

(C) К. кызы Али, 2021

Для цитирования: Гусева М.А., Андреева Е. Г., К. кызы Али. Виртуальный инструментарий для комплексной оценки качества одежды со сложнофактурной поверхностью // Территория новых возможностей. Вестник Владивостокского государственного университета экономики и сервиса. - 2021. - Т. 13, № 3. - С. 147-157.

For citation: Guseva M. A., Andreeva E.G., K. kyzy Aly. Virtual toolkit for a comprehensive assessment of the quality of clothing with a complex textured surface, The Territory of New Opportunities. The Herald of Vladivostok State University of Economics and Service, 2021, Vol. 13, № 3, pp. 147-157.

DOI https://doi.org/10.24866/VVSU/2073-3984/2021-3/147-157

Дата поступления: 23.08.2021. 